\title{
MONTAGENS TOPO-LÓGICAS: AS IMAGENS NOS CAPITÉIS E PILARES DO CLAUSTRO DE MOISSAC*
}

\author{
Maria Cristina Correia Leandro Pereira \\ Departamento de História da Faculdade de Filosofia, Letras e \\ Ciências Humanas da Universidade de São Paulo
}

\begin{abstract}
Resumo
A partir do conceito de "montagem", tomado de Georges Didi-Huberman, em suas releituras de Walter Benjamin e Aby Warburg, este artigo busca refutar a visão corrente na bibliografia especializada sobre o claustro românico de Moissac de que lhe faltaria uma "ordenação lógica" para seus capitéis. Ao contrário, mostraremos como este "lugar de imagens" é resultado de várias "montagens topo-lógicas".
\end{abstract}

\section{Palavras-chave}

Moissac $\bullet$ imagens $\bullet$ montagens.

\section{Contato:}

Departamento de História - FFLCH/USP

Av. Prof. Lineu Prestes, 338

Campus Universitário - São Paulo-SP - 05508-900

E-mail: mariacristinapereira@yahoo.com

* Todas as imagens mencionadas neste artigo estão reproduzidas no Caderno de imagens. 


\title{
TOPO-LOGICAL MONTAGES: THE IMAGES ON THE CAPITALS AND PILLARS OF THE CLOISTER OF MOISSAC
}

\author{
Maria Cristina Correia Leandro Pereira \\ Departamento de História da Faculdade de Filosofia, Letras e \\ Ciências Humanas da Universidade de São Paulo
}

\begin{abstract}
Based on George Didi-Huberman's concept of "montage", developed in his reading of Walter Benjamin and Aby Warburg, this article intends to refute the specialized bibliography on the cloister of Moissac that denies the existence of a logical order for its capitals. On the contrary, it will be demonstrated that this "place of images" is the result of several "topo-logical montages".
\end{abstract}

\section{Keywords}

Moissac $\bullet$ images $\bullet$ montages.

\section{Contact:}

Departamento de História - FFLCH/USP

Av. Prof. Lineu Prestes, 338

Campus Universitário - São Paulo - SP - 05508-900

E-mail: mariacristinapereira@yahoo.com 
O claustro de Moissac, ${ }^{1}$ no sudoeste da França, construído no final do século $\mathrm{XI},{ }^{2}$ é um dos mais antigos conservados quase integralmente e em seu lugar de origem. ${ }^{3}$ Alguns estudiosos do claustro, porém, como Raymond Rey e Jacques Hourlier, ${ }^{4}$ sugeriram que seus 76 capitéis não teriam mais a mesma disposição original. A principal motivação para esta hipótese é o fato de não existir uma ordenação linear - ou qualquer outra que possa ser imediatamente observada - entre esses capitéis: temas veterotestamentários, por exemplo, alternam-se com outros tirados do Novo Testamento, ou com cenas hagiográficas, ou com folhagens. No entanto, como buscaremos demonstrar ao longo deste artigo, tal expectativa é anacrônica e não leva em consideração a possibilidade de outros tipos de ordenação do pensamento (e, mais especificamente, do "pensamento figurativo" $)^{5}$ e de sua ancoragem espacial - o que designamos por "montagens topo-lógicas", conforme discutiremos mais adiante.

De modo geral, encontramos, na bibliografia especializada sobre o claustro de Moissac, uma dupla orientação. De um lado, estão os autores que defendem que a disposição original das imagens foi alterada - deixando implícito que haveria uma ordem lógica original - e de outro, os autores que sustentam que tal ordem jamais existiu. Os primeiros, a exemplo dos já citados Rey e Hourlier, ${ }^{6}$ creem poder localizar exatamente o momento em que se teria dado a desorganização: quando da reforma ocorrida no século XIII, que substituiu os arcos românicos por ogivais. Esta hipótese é, no entanto, bastante frágil. Em primeiro lugar, porque os monges que viviam em Moissac, tendo passado toda sua vida "ruminando" visualmente essas imagens, certamente saberiam reconstituir de memória a disposição original dos capitéis. ${ }^{7}$

1 Este trabalho em muito se beneficiou das contribuições provenientes das discussões e releituras de Eduardo Henrik Aubert, a quem expresso meus agradecimentos.

2 Segundo a inscrição no pilar central da galeria oeste, ele foi "feito" ("FACTVS EST") em 1100. Sobre as discussões historiográficas a respeito da datação, ver: PEREIRA, Maria Cristina C. L. Une pensée en images. Les chapiteaux du cloître de Moissac. Tese de doutorado, História, EHESS, Paris, 2001, p. 83-89.

3 Diferentemente do que ocorreu, por exemplo, com os claustros de Saint-Guillheme-le-Désert e de Saint-Michel de Cuxa, transferidos em parte para o Museu The Cloisters, em Nova Iorque.

4 REY, Raymond. Les cloîtres historiés du Midi dans l'art roman. Étude iconographique. Mémoires de la Société Archéologique du Midi de la France 23, 1955, p. 7-174, p. 37; HOURLIER, Jacques. La spiritualité à Moissac d'après la sculpture. In: Moissac et l'Occident au XI siècle. Actes du Colloque International de Moissac, 3-5 maio 1963. Toulouse: E. Privat, 1964, p. 71-80, p. 72.

5 Para usarmos a expressão cunhada por FRANCASTEL, Pierre. La figure et le lieu. L'ordre visuel du Quattrocento. Paris: Gallimard, 1967, p. 54-62.

6 REY, Raymond, op. cit., p. 37; HOURLIER, Jacques, op. cit., p. 72.

7 Além disso, como bem observou Leah Rutchick, a reforma do século XIII ocorrera em um momento de crise econômica do mosteiro, devendo ter sido realizada com um certo vagar, e se 
Além disso, ainda que se pudesse fazer uma simulação de rearranjo, virtual, de todos os capitéis, mesmo assim não se obteria uma sequência linear. E isso porque os capitéis não são todos iguais: oito deles possuem apenas três faces (e não quatro, como a maioria, já que eles têm um dos lados adossado a um dos pilares de ângulo das galerias), e, dos restantes, metade está apoiada sobre colunas simples e a outra metade, sobre colunas duplas (o que torna estes últimos maiores que os primeiros). Somente essa alternância obrigatória entre colunas simples e duplas já impediria uma ordenação linear e cronológica. Para ficarmos com um único exemplo, três capitéis relativos à história de Davi - combatendo Golias, sendo ungido rei e compondo os salmos - estão situados, respectivamente, sobre coluna dupla adossada, coluna simples e, novamente, coluna simples.

Considerando essa impossibilidade, outros autores perceberam que a ausência de ordenamento linear não poderia ser imputada à reforma do século XIII. A solução, portanto, foi se referir à ausência de lógica já na ordenação original. Assim afirmava Georges Gaillard:

O visitante atual se choca com a desordem dos capitéis, para os quais é impossível encontrar um fio lógico [...] Mas tampouco podemos afirmar que a disposição primitiva obedecesse a regras lógicas. Conhecemos muitos claustros em que os capitéis não foram mudados de seu lugar primitivo e nos quais a ordem está longe de ser perfeita. $\mathrm{O}$ acaso e a fantasia tiveram sua parte e, sem dúvida, isso surpreendia menos aos monges da Idade Média que a nós. ${ }^{8}$

Quer se tratasse do século XIII, que aceitaria como natural uma "desordenação lógica" daquele lugar de imagens, quer se tratasse do século XI, desprovido de "regras lógicas" e de "ordem perfeita", de toda forma, a visão que a maioria desses historiadores demonstram ter da Idade Média é a de uma época em que reinavam o acaso e a fantasia, como descreve Gaillard, reproduzindo a ideia romântica de uma Idade Média livre e fantasiosa.

utilizando talvez de mão-de-obra dos próprios monges. RUTCHICK, Leah. Sculpture programs in the Moissac cloister: benedictine culture, memory systems, and liturgical performance. Tese de doutorado, Universidade de Chicago, 1991, p. 76-80.

8 GAILLARD, Georges. El claustro y el pórtico de Moissac. In: Idem. Études d'art roman. Paris: PUF, 1972, p. 417-429, p. 28: "Al visitante actual le choca el desorden de los capiteles, en los cuales es imposible encontrar un hilo lógico. [...] Pero tampoco podemos afirmar que la disposición primitiva obedecía a reglas lógicas. Conocemos muchos claustros en los que los capiteles no se han movido de su primitivo emplazamiento y en los que el orden está lejos de ser perfecto. El azar y la fantasía han tenido su parte y, sin duda, a los monjes de la Edad Media esto les sorprendia menos que a nosotros". 
Na citação deste autor, quase todos os lugares-comuns referentes às imagens e ao imaginário medieval estão presentes - só faltando a comparação com a "Bíblia dos iletrados" que será, no entanto, encontrada em um texto sobre um outro claustro que tampouco apresentava um fio condutor narrativo único na disposição de seus capitéis, o de Sant Cugat del Vallès:

Esta hipótese [que busca uma ordenação narrativa] parece tanto mais aceitável quando aplicada a tempos nos quais os homens, em sua maioria analfabetos, necessitavam "ver" claramente representados os temas que eram propostos à sua consideração. ${ }^{9}$

Esta interpretação, que se utiliza abusivamente da fórmula gregoriana da imagem como educação dos ilitterati, ${ }^{10}$ é completamente descabida. Afinal, há que se lembrar que o claustro, contrariamente às igrejas, não era destinado a ser frequentado pelo público em geral, mas por monges, homens que, no caso do monasticismo beneditino, conheciam as letras e que deviam ler a Bíblia, como recomendava sua Regra. ${ }^{11}$

9 REVILLA, Fernando. Hacia una interpretación de los claustros románicos: el discurso edificante en Sant Cugat del Vallés. Goya 208, 1989, p. 200-208. p. 200: "Esa hipotésis parece tanto más aceptable aplicada a unos tiempos cuando los hombres, en su mayoría analfabetos, necesitaban 'ver' claramente representados los temas que se propusieran a su consideración'.

${ }^{10}$ De acordo com as famosas cartas do papa Gregório Magno ao bispo Sereno de Marselha: "Pinturas são usadas em igrejas para que aqueles que são ignorantes das letras possam pelo menos ler vendo nas paredes o que não podem ler nos livros" (“Idcirco enim pictura in ecclesiis adhibetur, ut hi qui litteras nesciunt saltem in parietibus uidendo legant, quae legere in codicibus non ualent."). GREGORIUS MAGNUS. Registrum epistularum. Epistola ad Serenus. IX, 209. Turnhout: Brepols, 1982 (CCSL 140A). E também: "Uma coisa, em efeito, é adorar uma pintura, e outra, é aprender por uma cena representada em pintura o que se deve adorar. Porque o que a escrita proporciona às pessoas que leem, a pintura oferece aos iletrados que a olham, porque esses ignorantes veem aí o que devem fazer; aqueles que não conhecem as letras leem aí, de modo que a pintura desempenha o papel da leitura, sobretudo entre os pagãos" "“Aliud est enim picturam adorare, aliud per picturae historiam quid sit adorandum addiscere. Nam quod legentibus scriptura, hoc idiotis praestat pictura cernentibus, quia in ipsa ignorantes uident quod sequi debeant, in ipsa legunt qui litteras nesciunt; unde praecipue gentibus pro lectione pictura est."). GREGORIUS MAGNUS. Registrum epistularum.Epistola ad Serenus. XI, 10. Turnhout: Brepols, 1982 (CCSL 140A). De modo geral, essas cartas de Gregório Magno seriam repetidas à exaustão pela Igreja, sendo encontrados ecos seus até no Concílio de Trento, por exemplo. Ver, a esse respeito: DUGGAN, Lawrence D. Was art really the book of illiterate?. Word and image 5, 1989, p. 227-251; CHAZELLE, Celia M. Pictures, books and the illiterate. Pope Gregory's letters to Serenus of Marseille. Word and Image 6, 1990, p. 138-153; CAMILLE, Michael. The Gregorian definition revisited: writing and the medieval image. In: BASCHET, Jérôme; SCHMITT, Jean-Claude (dir.). L'image. Fonctions et usages des images dans l'Occident médiéval. Paris: Le Léopard d'Or, 1996, p. 89-101.

${ }^{11}$ Benedicti Regula monachorum, 9-18. In: VOGUÉ, A. (ed.). La Règle de Saint Benoît. Paris: Cerf, 1972, p. 510-535 (Col. Sources Chrétiennes, 182). 
No caso de Moissac, apesar das frequentes acusações de falta de ordem (Jean Wirth $^{12}$ - ou de "desordem relativa", como relativiza Éliane Vergnolle),${ }^{13}$ de falta de lógica (Yves Christie) $)^{14}$ e de falta de racionalidade (M. F. Hearn $)^{15}$ na ordenação dos capitéis, ainda assim, alguns autores não se furtaram a tentar encontrar uma chave que resolveria o "mistério" de Moissac. Esta, para Hourlier, residiria na história da redenção, que ele encarrega o visitante de reconstituir em seu espírito. ${ }^{16}$ Essa narrativa, porém, não chega a abarcar dez capitéis - mas engloba o tímpano e o pórtico, conjuntos que foram feitos depois, para públicos e locais bem distintos. Quanto a Émile Mâle, apesar de afirmar que "não há nenhuma ordem lógica na escultura dos capitéis", ${ }^{17}$ ainda assim sugere que haveria um guia, algum manuscrito, que teria norteado as escolhas das imagens. Novamente, deparamo-nos com uma postura metodológica questionável, apesar de ainda muito difundida entre os historiadores da arte, a de conceder ao texto uma preeminência sobre as imagens, buscando nele a origem e a explicação das imagens. ${ }^{18}$

Em estudos monográficos sobre o claustro, também se encontra a mesma busca pela "ordem oculta", na expressão de Raymond Rey, ${ }_{19}^{19}$ que acaba por sugerir apenas associações, sobretudo tipológicas, entre alguns capitéis, reunindo

${ }^{12}$ WIRTH, Jean. L'image à l'époque romane. Paris: Cerf, 1999, p. 239.

${ }^{13}$ VERGNOLLE, Éliane. L'art roman. Paris: Flammarion, 1994, p. 261.

${ }^{14}$ CHRISTE, Yves. The Apocalypse in the monumental art of the Eleventh through the thirteenth centuries. In: EMMERSON, Richard K.; McGINN, Bernard (ed.). The Apocalypse in the Middle Ages. Ithaca/Londres: Cornell University Press, 1992, p. 234-258, p. 240. O autor utiliza essa expressão especificamente quando se refere às imagens do Apocalipse no claustro - tema de seu artigo - mas isso já é bastante significativo. Ele repete sua opinião mais adiante no mesmo texto: "it appears to be disordered" (CHRISTE, Yves, op. cit., p. 244).

${ }^{15}$ HEARN, Millard F. Romanesque sculpture. The revival of monumental stone sculpture in the XIth and XIIth centuries. Oxford: Phaidon, 1981, p. 123.

${ }^{16}$ HOURLIER, Jacques, op. cit., p. 72 ; 75-77. Ele utiliza todo esse conjunto em sua narrativa da redenção, a partir do capitel de Adão e Eva, passando pelo de Caim e Abel, pelas prefigurações do triunfo do Cristo (Davi e o personagem enfrentando o dragão no nártex); chegando à queda da Babilônia, seguida pelo advento da Jerusalém celeste, o triunfo da cruz e o Cristo tronando no tímpano.

${ }^{17}$ MÂLE, Émile. L'art religieux du XIIe siècle en France. Étude sur les origines de l'iconographie du Moyen Âge. Paris: A. Colin, 1922, p. 9-13.

${ }^{18}$ Ao contrário, como argumentava Aby Warburg, o que existe entre texto e imagem não é uma dependência da segunda ao primeiro, mas uma "natural correspondência" ("Zusammengehörigkeit", ou "conexidade", na tradução de DIDI-HUBERMAN, Georges. O que vemos, o que nos olha. São Paulo: 34, 1998, p. 181). WARBURG, Aby. Arte del retrato y burguesía florentina. Domenico Ghirlandaio en Santa Trinita. Los retratos de Lorenzo de Medici y de sus familiares. In: Idem. El renacimiento del paganismo. Aportaciones a la historia cultural del Renacimiento europeo. Madri: Alianza, 2005, p. 147-175, p. 149.

${ }^{19}$ REY, Raymond, op. cit., p. 37. Ou, como disse o cônego Pierre Sirgant, sua "chave". SIRGANT, Pierre. Moissac. Bible ouverte. Montauban: Color Press, 1996, p. 35. 
tematicamente os capitéis escatológicos, os teofânicos, os hagiográficos etc. ${ }^{20}$ Em uma tese de doutorado relativamente recente, Benedict Forndran crê ter mais sucesso, fornecendo duas "chaves" (Schlüsseldarstellungen) para a disposição dos capitéis do claustro: uma seguindo os ciclos astrológicos e a outra segundo o calendário das festas dos santos. ${ }^{21}$ Mas, como o próprio autor reconhece, as exceções a esses dois esquemas são bastante numerosas, o que inviabiliza seu caráter de chave para explicação global.

Percebemos, por meio desses exemplos, que tal caminho, de associações locais, parciais, que poderia levar a resultados mais satisfatórios, é menosprezado pelos autores que insistiam em encontrar uma única ordem - busca essa sempre frustrada, como desabafou Marguerite Vidal, outra importante estudiosa do claustro, que crê que existe uma ordem oculta:

[...] parece-me bastante delicado fixar, e ainda menos, impor uma ideia diretora, unindo no plano teológico ou moral esses diversos elementos [...]. Nós não podemos discutir aqui, mas admitamos que, sob uma desordem aparente, deva existir uma continuidade secreta cuja precisão permanece para sempre perdida. ${ }^{22}$

Um exemplo quase caricatural dos dois polos de interpretação, um que se ilusiona com a perspectiva de uma ordenação única, mas misteriosa, oculta, e o outro que nega que ela possa existir, se encontra em outra tese, a de Régis de la Haye, que se pergunta logo de início:

O claustro de Moissac possui um tema diretor ou é uma "coleção" não-temática? Uma deambulação no claustro se assemelha ao passeio descosturado dos Quadros de uma exposição, de Mussorgsky, uma sucessão, uma justaposição de quadros, bem diferentes uns dos outros, ligados apenas pelo tema musical do passeio? Ou, ao contrário, o claustro constitui uma unidade temática como a Via Crucis de Franz Liszt? Há um tema diretor? ${ }^{23}$

A resposta negativa a essa questão frustra sua expectativa anacrônica de achar o equivalente de uma Via Crucis, com as imagens dispostas em uma sequência

${ }^{20}$ REY, Raymond, op. cit., p. 37-67.

${ }^{21}$ FORNDRAN, Benedict. Die Kapitellverteilung des Kreuzgangs von Moissac. Disposition und Funktion der Skulptur eines kluniazensischen Kreuzgangs. Tese de doutorado, Universidade de Bonn, 1997, p. 54-65.

${ }^{22}$ VIDAL, Marguerite. Moissac. In: Idem; MAURY, Jean; PORCHER, Jean. Quercy roman. Yonne: Zodiaque, 1959, p. 42-135, p. 130: “[...] il semble bien délicat de fixer, encore moins d'imposer une idée directrice, unissant sur le plan théologique ou moral ces divers éléments. [...] Nous n'en pouvons discuter ici, mais admettons que, sous un désordre apparent, doit exister une continuité secrète dont la précision reste, sans doute, à jamais perdue".

${ }^{23} \mathrm{DE}$ LA HAYE, Régis. Apogée de Moissac. L'abbaye de S. Pierre de Moissac à l'époque de la 
linear, e seguindo um objetivo específico - e que lembra um pouco o de Hourlier: demonstrar a crucifixão, o sacrifício e, depois, a redenção. Essa sequência, que não é encontrada, fá-lo se voltar à segunda analogia anacrônica, que compara os capitéis a quadros de uma exposição, sem ordenação coerente. As relações das imagens com seus lugares, suas funções e interrelações são ignoradas, e o claustro seria uma coleção de imagens, como em um museu. ${ }^{24}$

De certa forma, a maioria dos autores citados acima parece terem sido influenciados pela utilização atual do claustro - por turistas que fazem o circuito das quatro galerias, acompanhados por guias que lhes explicam as imagens tomando sua recepção atual como válida para todas as épocas.

Além das óbvias diferenças de público e de funções do claustro, estão também em jogo diferentes formas de utilização do claustro: a presença do guia, os discursos daí decorrentes e a deambulação, atividades características do claustro na atualidade, após ter sido secularizado durante a Revolução Francesa e transformado em monumento nacional, em $1850 .^{25}$

Essas atividades eram diametralmente opostas ao que se esperava do comportamento de um monge na Idade Média, como se pode depreender da leitura de estatutos e costumários cluniacenses. Além da evidente ausência de guias (e de qualquer referência a uma didática das imagens nessas fontes), encontramos uma ênfase na ausência de conversas e de deambulações (com exceção das procissões que ocorriam no interior do claustro aos domingos, nos dias de festas e durante a Quaresma) ${ }^{26}$ Nessas fontes também se recomendava a utilização do claustro como local para leitura, para meditação e para a prática do canto - atividades sempre

construction de son cloître et de son grand portail. Tese de doutorado, Université Catholique de Nimègue, Maastricht, 1995, p. 14: "Le cloître de Moissac possède-t-il un thème directeur, ou est-il une 'collection non-thématique?' Une déambulation dans le cloître ressemble-t-elle à la promenade décousue des Tableaux d'une exposition de Moussorgsky, une suite, une juxtaposition de tableaux, très différents les uns des autres, reliés seulement par le thème musical de la promenade? Ou, au contraire, le cloître constitue-t-il une unité thématique comme la Via Crucis de Franz Liszt? Y a-t-il un thème directeur?".

${ }^{24}$ De certa forma, as conclusões de De La Haye se aproximam das de Wayne Dynes, quando este descreveu o claustro românico como "mais uma coleção de ícones que a organização estrita de uma fachada de igreja" ("more a colection of icons than the strict organization of a church façade"). DINES, Wayne. The medieval cloister as the Portico of Salomon. Gesta 12/1, 1973, p. 61-69, p. 68. É inútil querer encontrar a mesma forma de pensar o espaço, de pensar as imagens, quando se trabalha com lugares distintos: as paredes de uma igreja, seu tímpano, ou os capitéis de um claustro possuem funções, públicos e suportes diferentes.

${ }^{25}$ VIDAL, Marguerite, art. cit., p. 48.

${ }^{26}$ Ver, a esse respeito, entre outros, MEYVAERT, Paul. The medieval monastic claustrum. Gesta 12, 1973, p. 53-59, p. 55. 
acompanhadas pelo verbo sedere. ${ }^{27}$ À imagem do monge ideal, segundo a Regra beneditina, ${ }^{28}$ não se deveria ser giróvago nem mesmo no interior do claustro.

Contudo, mais problemática que essa concepção anacrônica de utilização do claustro é a conclusão a que chega De La Haye na conclusão de sua tese, como o título do capítulo, "A irracionalidade do claustro", já deixa entrever:

Na realidade, o claustro se parece bastante bem com o passeio descosturado dos Quadros de uma exposição de Mussorgsky de que eu falava no início deste estudo. Se há coerência, ela não é racional. Ela é irracional como era todo o século XI. ${ }^{29}$

Há vários perigos nessas afirmações, que hiperbolizam as já citadas acusações de ausência de lógica no claustro. Trata-se de um exemplo extremo de anacronismo, com o julgamento de todo um século segundo parâmetros que são de outro momento histórico. Não se pode pretender encontrar os mesmos sistemas de pensamento em todas as épocas ${ }^{30}$ e nem, por outro lado, pensar que as sociedades que funcionam de outros modos são desprovidas de suas lógicas, de suas coerências, em suma, de racionalidade - tomando este termo com as precauções indicadas por Jean-Pierre Vernant, de que "não há uma razão, mas formas de racionalidade, técnicas de pensamento, de cálculo, de escrita". ${ }^{31}$

Assim como não acreditamos na existência de uma ordem oculta, mistério, ou um "código" do claustro de Moissac, tampouco vemos aí uma ausência de lógica ou de racionalidade e nem uma desordem (original ou datando do século XIII). A narratividade, a linearidade não são as únicas formas possíveis de ordenação e, ainda que, em alguns claustros, a disposição das imagens tenha seguido essa lógica (como é o caso do claustro de San Juan de La Peña, na Huesca), ${ }^{32}$

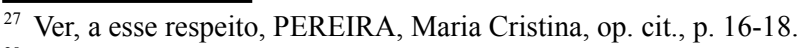

${ }^{28}$ Benedicti Regula monachorum, 1, 10-11 "O quarto gênero de monges é o dos chamados giróvagos, porque passam a vida inteira viajando por várias províncias, hospedando-se durante três ou quarto dias nos mosteiros. Sempre vagando e nunca estáveis, limitam-se a servir suas próprias vontades e os deleites da gula" ("Quartum verum genus est monachorum, quod nominatur girovagum, qui tota vita sua per diversas províncias, ternis aut quaternis diebus per diversorum cellas hospitantur, semper vagi et nunquam stabiles, et propriis voluntatibus et gulae inlecebris servientes").

${ }^{29}$ DE LA HAYE, Régis, op. cit., p. 499: "En réalité, le cloître ressemble bel et bien à la promenade décousue des Tableaux d'une Exposition de Moussorgsky, dont je parlais au tout début de cette étude. S'il y a cohérence, elle n'est pas rationnelle. Elle est irrationnelle comme l'était le XIe siècle".

${ }^{30}$ Ver a obra fundamental, nesse sentido, de LÉVI-STRAUSS, Claude. La pensée sauvage. Paris: Plon, 1962, em part. o cap. 1.

${ }^{31}$ VERNANT, Jean-Pierre. La volonté de comprendre. Paris: L'Aube, 1999, p. 43.

${ }^{32} \mathrm{O}$ caso do claustro de San Juan de la Peña, em Huesca, posterior à Moissac, datando do fim do século XII, é bem diferente. Quase que na totalidade de seus capitéis, que se alternam entre duplos e simples, das galerias norte e leste há uma sequência cronológica dos Evangelhos: três capitéis seguidos mostram a criação de Eva, a tentação, Adão e Eva ao trabalho e os sacrifícios 
não há regras e nem exclusividade. Afinal, ao contrário do que pensam De La Haye e vários outros autores, no mundo feudal, como analisa Alain Guerreau, "o espaço não era concebido como contínuo e homogêneo, mas como descontínuo e heterogêneo, no sentido de que era em toda parte polarizado". ${ }^{33} \mathrm{O}$ claustro de Moissac é um exemplo perfeito dessa forma de conceber o espaço, com seus capitéis e pilares formando grupos, constituindo polos de imagens segundo lógicas temático-funcional-espaciais.

Podemos falar, então, em uma série de "montagens topo-lógicas", fórmula que associa algumas questões importantes, enfatizando-as: a afirmação da existência de lógica - e de racionalidade - no claustro; a importância assumida pela disposição espacial das imagens (seja em relação a determinadas partes do claustro, seja por suas relações com outras imagens no interior do claustro); e, por fim, a ideia de montagem, conforme definida por Georges Didi-Huberman, a partir de sua leitura de Walter Benjamin: ${ }^{34}$

A montagem [...] não é a criação fictícia de uma continuidade temporal a partir de planos descontinuados arranjados em sequências. É, ao contrário, uma forma de desdobrar visualmente as descontinuidades do tempo que operam em toda sequência de história. ${ }^{35}$

Advindo do cinema, o conceito de montagem se refere a um procedimento de rearranjo, de desmontagem do todo em fragmentos descontínuos (já que tirados do todo) que são, em seguida, selecionados e rearranjados, mas de forma a conferir-lhes um (novo) sentido que não é o sentido do todo da experiência (que, no limite, é um não-sentido), mas um sentido possível.

A grande diferença do que propomos em nosso estudo em relação à definição tradicional de montagem aplicada no cinema (e que Didi-Huberman frisa nessa

de Caim e Abel. Depois, há treze capitéis apresentando a vida do Cristo, da anunciação à última ceia. Pamela A. Patton, que estudou esse claustro, considera-o como o primeiro exemplo, para a época românica, de um programa único e linear dos capitéis. PATTON, Pamela A. The capitals of San Juan de la Peña: narrative sequence and monastic spirituality in the romanesque cloister. Studies in iconography 20, 1999, p. 51-100, p. 51.

${ }^{33}$ GUERREAU, Alain. Quelques caracteres spécifiques de l'espace féodal européen. In: Idem et al. (ed.). L'État ou le roi. Les fondations de la modernité monarchique en France (XIV-XVII siècles). Paris: MSH, 1996, p. 85-101, p. 87: “l'espace n'était pas conçu comme continu et homogène, mais comme discontinu et hétérogène, en ce sens qu'il était à chaque endroit polarisé".

${ }^{34}$ DIDI-HUBERMAN, Georges. Devant le temps. Histoire de l'art et anachronisme des images. Paris: Minuit, 2000. p. 119-127.

${ }^{35}$ DIDI-HUBERMAN, Georges. L'image survivante. Histoire de l'art et temps des fantômes selon Aby Warburg. Paris: Minuit, 2002. p. 474: “Le montage [...] n'est pas la création factice d'une continuité temporelle à partir de 'plans'discontinus agencés en séquences. C'est, au contraire, unefaçon de déplier visuellement les discontinuités du temps à l'oeuvre dans toute séquence d'histoire". 
passagem) é que não estamos lidando aqui com uma descontinuidade temporal ${ }^{36}$ - já que todas as imagens do claustro foram feitas e dispostas (e, como já argumentamos, assim o permanecem) na mesma época. Quando muito, poderíamos falar em uma descontinuidade cronológica no "interior" das imagens, ou seja, em suas temáticas. Trata-se, mais bem, de uma descontinuidade espacial, no sentido de que falava Guerreau, com a qual a montagem vai lidar, dobrando e desdobrando lugares. Afinal, o claustro é feito das várias imagens associadas à distância, ou lado a lado, interligadas, constituindo uma série de lugares, de polos, de tramas.

De certa forma, essa ideia de montagem que propomos se aproxima mais do método de trabalho de Aby Warburg - e que é perceptível claramente, por exemplo, na confecção de seu Atlas ${ }^{37}$-, como descreve Didi-Huberman:

Era necessário, pois, inventar uma forma nova de coleção e de exibição. Uma forma que não fosse nem arrumação (rangement) (que consiste em colocar junto coisas que sejam as menos diferentes possível, sob a autoridade de um princípio de razão totalitário) nem bagunça (bric-à-brac) (que consiste em colocar junto coisas as mais diferentes possível, sob a não-autoridade do arbitrário). [...] Chamemos essa forma uma montagem. ${ }^{38}$

O claustro é também, pois, uma montagem - ou um conjunto de montagens - de imagens que parecem incoerentes à primeira vista, ou para um olhar anacrônico, mas que são prenhes de sentidos e mostram a construção daquele ambiente específico, segundo diversas necessidades, interesses, funções - demonstrando a complexidade daquele sistema lógico, lembrando, como bem observou LéviStrauss, que "quem diz lógica, diz instauração de relações necessárias". ${ }^{39}$ É disso, pois, que se trata: "relações necessárias", e não "razão totalitária” ou "não-autoridade do arbitrário".

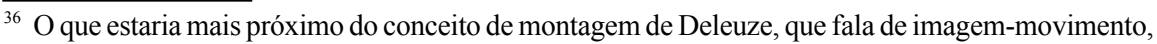
de imagem do tempo, tendo como referência o cinema. DELEUZE, Gilles. L'image-mouvement. Paris: Minuit, 1983, p. 46-82.

${ }^{37}$ Em seu Bilderatlas Mnemosyne (Atlas de Imagens Mnemosine), que permaneceu inconcluso (como não poderia deixar de ser, já que se tratava mais de um método que de uma obra autôno$\mathrm{ma}$ ), Warburg estabelecia relações entre imagens, agrupadas em grandes pranchas, servindo para expor e, ao mesmo tempo, construir suas análises de imagens, notadamente em torno das ideias de Nachleben, de "sobrevivência" das formas. Parte do Atlas foi publicada: ver, em espanhol, WARBURG, Aby. Atlas Mnemosyne. Madri: Akal, 2010.

${ }^{38}$ DIDI-HUBERMAN, Georges, L'image survivante, op. cit., p. 474: "Il fallait donc inventer une forme nouvelle de collection et de monstration. Une forme qui ne fût ni rangement (qui consiste à mettre ensemble des choses les moins différentes possibles, sous l'autorité d'un principe de raison totalitaire) ni bric-à-brac (qui consiste à mettre ensemble des choses les plus différentes possibles, sous la non-autorité de l'arbitraire). [...]. Nommons cette forme un montage".

${ }^{39}$ LÉVI-STRAUSS, Claude, op. cit., p. 48: "Qui dit logique, dit pourtant instauration de relations nécessaires". 
A fim de examinarmos brevemente algumas dessas montagens, que colocam as imagens em diferentes gêneros de relações, apresentaremos alguns casos, começando pelo conjunto das imagens nos pilares.

O subgrupo das imagens esculpidas em mármore, em relevo pouco saliente, nas faces internas dos pilares dos ângulos do claustro, nas extremidades das galerias, é o mais homogêneo de todo o claustro, tanto pela temática quanto pelos aspectos estilísticos: estão aí representados oito apóstolos, dois em cada pilar [fig. 1, pág. 245]. Fica assim materializada a concepção de Paulo de que os apóstolos são as colunas da Igreja (Ga 2,9) - aqui, do claustro. ${ }^{40}$ Além de tomarem parte na sustentação física do claustro, essas imagens também funcionam como pontos de sustentação simbólica da comunidade, servindo para a construção e afirmação de sua identidade coletiva. E isso é de especial importância considerando o contexto da época, quando monges beneditinos e cônegos agostinianos disputavam qual desses dois modos de vida seguia mais de perto o ideal de vita apostólica ${ }^{41}$ No contexto específico de Moissac, essa concorrência tomou proporções bem destacadas, quando seus monges disputaram com os cônegos de Saint-Sernin de Toulouse, no final do século XI, o controle daquela igreja e, consequentemente, do túmulo do mártir patrono de Toulouse. ${ }^{42}$ A presença do colégio apostólico no interior do claustro, a apropriação dos apóstolos pela comunidade monástica explicitavam sua posição político-religiosa. Ademais, a esse grupo se somava o primeiro abade cluniacense de Moissac, Durand, ${ }^{43}$ também figurado em relevo em um pilar (embora não de ângulo), à maneira dos apóstolos [fig. 2, pág. 246]. Ou seja, a comunidade de Moissac possuía um representante - e não qualquer um - elevado à posição de isoapóstolo.

${ }^{40}$ Há várias outras passagens que também fazem associação com os apóstolos a pedras angulares (S1 118, 22; Mt 21, 42; At 4, 11), o que só mostra o peso dessa montagem específica.

${ }^{41}$ Ver, entre outros, VICAIRE, Marie-Hubert. L'imitation des apôtres. Moines, chanoines et mendiants. IVe-XIIIe siècles. Paris: Cerf, 1963.

${ }^{42}$ Após a entrega da igreja aos monges de Moissac pelo bispo de Toulouse, os cônegos recorreram ao papa e conseguiram reverter a anexação, expulsando de lá os monges. Ver, a esse respeito, MAGNOU, Elizabeth. Le chapitre de la cathédrale Saint Étienne de Toulouse (fin XI-début XI siècle). In: La vita comune del clero nei secoli XI e XII. Milão: Vita e Pensiero, 1962, v. 2, p. 110-114.

${ }^{43} \mathrm{O}$ mosteiro de Moissac foi anexado à ecclesia cluniacense em 1048 (data estabelecida por HOURLIER, Jacques. L'entrée de Moissac dans l'Ordre de Cluny. In: Moissac et l'Occident au XI siècle, op, cit., p. 25-35), sendo Durand, antigo monge de Cluny e parente de Odilon, o primeiro abade após a reforma. A inscrição no arco acima de sua cabeça traz seu "currículo", identificando-o como abade de Moissac, bispo de Toulouse e santo - embora ele não constasse de nenhum hagiológico, nem mesmo de Toulouse: "S(AN)C(TV)S DVRANNVS E(PISCO)P(V)S TOLOSANVS ET ABB(A)S MOYSIACO". 
Durand, além de ser integrado ao colégio apostólico, também participava de uma outra montagem: o relevo com sua imagem está posicionado de frente para a antiga porta da sala capitular. ${ }^{44}$ Essa disposição era reforçada pelo fato de que o abade está figurado de frente, característica que o distingue dos apóstolos, que estão todos de três quartos, cada um olhando para o par com o qual divide o pilar. Assim, se a posição do corpo de Durand minimiza seu pertencimento ao grupo dos apóstolos, ela sublinha sua relação com aquele lugar, onde quotidianamente a Regra beneditina, o martirológio e o necrológio eram lidos, onde o trabalho manual era distribuído, as culpas eram confessadas e as punições eram aplicadas. ${ }^{45}$ Ninguém melhor que Durand, portanto, o responsável pela introdução da nova disciplina na comunidade, para estar figurado em frente à entrada da sala capitular. Em uma relação dialética, a imagem de Durand contribuía para criar a atmosfera de autoridade necessária àquela sala e a aura de autoridade emanando daquela sala ajudava a conservar a memória do primeiro abade cluniacense de Moissac. A força dessa montagem, assim como, de certa forma, sua eficácia podem ser observadas quando, alguns séculos mais tarde, o cronista do mosteiro, Aymeric de Peyrac, ao discorrer sobre os feitos daquele abade, não deixou de notar a disposição de sua imagem em frente àquela sala. ${ }^{46}$

Outra porta importante no claustro era a que dava acesso à igreja. Quase em frente a ela, no encontro entre a prestigiosa galeria leste (devido à presença da sala capitular) e a galeria colada à igreja, estão posicionados os patronos de Moissac, Pedro e Paulo - assim escolhidos após o ingresso do mosteiro na ecclesia cluniacense. ${ }^{47}$ Neste lugar simbolicamente forte, a união dos dois espaços principais do mosteiro se repete na justaposição de duas chaves na mão de Pedro

${ }^{44}$ Atualmente, a porta não está mais diante do pilar, tendo sido deslocada para a direita provavelmente no século XVII. VIDAL, Marguerite, art. cit., p. 49.

${ }^{45}$ Ver, a esse respeito: LECLERCQ, Henri. Chapitre monastique. In: Idem; CABROL, Fernand. Dictionnaire d'archéologie chrétienne et de liturgie. Paris: Letouzey, 1934, t. 3/1, col. 508; LEMAÎTRE, Jean-Loup. Liber capituli. Le livre du chapitre, des origines au XVIe siècle. L'exemple français. In: SCHMID, Karl; WOLLASCH, Joachim (ed.). Memoria. Der geschichtliche Zeugniswert des liturgischen Gedenkens im Mittelalter. München: W. Fink, 1984, p. 625-648, p. 633.

${ }^{46}$ Segundo o cronista da passagem do século XIV para o XV, essa havia sido a forma encontrada por seu sucessor e construtor do claustro, Ansquitil, para homenageá-lo: "Et ad maiorem gestorum domnus Isquillinus, successor suus, fecit ipsum in claustro devotissime per ipsum edifficato opere sumptuoso in quadam ymagine marmoreo lapide ante capitulum sculpari": "E para comemorar seus grandes feitos, dom Ansquitil, seu sucessor, fez, no claustro que ele havia construído devotadamente e com trabalho suntuoso, esculpir sua imagem em mármore frente à sala capitular". AYMERICUS DE PEYRACO. Chronicon. BNF Lat. 4991A, fol. 158rb, 26-27.

${ }^{47}$ Desde sua fundação, no século VII, até a anexação, o mosteiro fora dedicado apenas a São Pedro. A mudança de patronos é claramente perceptível nas cartas de doações ao mosteiro. 
(em lugar de uma só, como era mais comum na iconografia). Poderíamos falar em uma "montagem de convergência": ${ }^{48}$ entre dois santos, dois lugares no mosteiro e duas casas monásticas, Moissac e Cluny. De certa forma, ela também ecoa a montagem que posiciona Durand de frente para a sala capitular. Mas, neste último caso, trata-se de uma relação mais local, quase "doméstica", enquanto, no outro, o alcance é maior: os santos protetores do mosteiro e de toda a congregação. Em ambos os casos, porém, estão em jogo questões de exibição de poder, de status e de pertencimento, vinculando santos importantes para a comunidade a lugares de prestígio e, sobretudo, de passagem, de circulação.

O mesmo relevo de Durand participa ainda de uma terceira montagem: a do subgrupo de pilares no centro das galerias. Eles também estão associados de acordo com uma lógica que é reforçada por sua localização espacial. Há dois eixos claramente marcados: leste-oeste e norte-sul.

No primeiro, que poderíamos chamar de eixo comemorativo e instituidor, são exibidos, em uma extremidade, o abade Durand e, na outra, a inscrição informando a datação do claustro e o nome de seu construtor (Ansquitil), ${ }^{49}$ além de um báculo e uma cruz. Ou seja, o claustro apresenta, neste eixo leste-oeste, elementos chaves para a elaboração, exibição e preservação da memória de sua construção: o abade que criou as condições para tal ação e o outro abade que a levou a cabo, além da data da construção. Os dois pilares traduzem, pois, algumas das dimensões mais significativas do conceito de memoria para o cristianismo medieval: a memorização (os nomes e a data), a comemoração (notadamente com as inscrições epigráficas prestigiosas) e a atualização (entre Durand e Ansquitil e entre a cruz e o báculo). ${ }^{50}$

O outro eixo, norte-sul, é ornamental: em uma extremidade, um pilar coberto por motivos geométricos variados (um tipo diferente em cada lado: ondulações

\footnotetext{
${ }_{48}$ Inspirando-nos no conceito de "montagem convergente" que, de acordo com Deleuze, caracteriza um dos tipos principais de montagem do diretor americano D. W. Griffith. DELEUZE, Gilles, op. cit., p. $49 ; 56$.

49 “ANNO AB INCARNA /TIONE AETERNI / PRINCIPIS MILLESIMO / CENTESIMO FACTV(M) / EST CLAVSTR(VM) ISTVD / TEMPORE / DOM(I)NI / ANSQVITILII / ABBATIS / AMEN /VVV / $M D M / R R R / F F F "$. O cuidado com o desenho das letras traçadas no mármore é mais um indício da preocupação estético-ornamental dos monges que conceberam o claustro, e da importância da informação que é através delas prestada. As quatro últimas linhas, até hoje não "decifradas" pelos estudiosos, contribuiriam, em nosso entender, para atribuir um aspecto ainda mais marcantemente monumental, e mesmo antiquizante, ao pilar. Ver, a esse respeito, PEREIRA, Maria Cristina, op. cit., p. 132-135.

${ }^{50}$ Sobre esse tema, ver, entre outros: GEARY, Patrick J. Memória. In: LE GOFF, Jacques e SCHMITT ,Jean-Claude (org.). Dicionário temático do Ocidente medieval. São Paulo: Imprensa Oficial/Edusc, 2002, v. 2, p. 167-181.
} 
e duas variações de semicírculos evocando escamas de peixe),${ }^{51}$ e, na outra, um pilar anicônico, em mármore rosa. Estão evocados, nesta nova montagem, dois tipos de beleza: a do trabalho artístico e a do próprio material. Enquanto a pedra nua tem aqui sua única ocorrência no claustro, os motivos ornamentais no outro pilar são mais comuns. Alguns ábacos os apresentam também, o que mostra, mais uma vez, que essas montagens não são excludentes, um mesmo pilar ou um mesmo capitel pode participar de mais de uma delas. E os entrecruzamentos não são incomuns, como o relevo de Durand o demonstra bem - e não é de causar surpresa que ele seja ladeado, em seu pilar, por duas placas de mármore cobertas com esses motivos ornamentais em escama de peixe. ${ }^{52}$ De acordo com Aymeric de Peyrac, esses motivos em escama de peixe, frequentes no claustro, ${ }^{53}$ seriam uma espécie de evocação simbólica do abade Ansquitil: etimologicamente, seu nome viria de "scatos picium", escamas de peixe, e essa seria, pois, uma forma de deixar sua marca em vários locais do claustro. ${ }^{54} \mathrm{E}$, dentre eles, de maneira politicamente significativa, a se acreditar na etimologia de Aymeric, no pilar de Durand.

Passando agora para os capitéis, inicialmente para aqueles que são adossados aos pilares nos ângulos, encontramos uma montagem que engloba todos eles. $\mathrm{O}$ pano de fundo é o Cristo: além de cenas de sua vida (a anunciação, o batismo e o encontro com a samaritana), há diferentes personagens que o prefiguram. São eles: Sansão (combatendo o leão), Davi (combatendo Golias), S. Miguel (pisando sobre o dragão), Isaac (na iminência de ser sacrificado) e João Batista (sendo degolado). É interessante observar que todas as personagens associadas tipologicamente ao Cristo participam de cenas de confrontação, como vítimas (mas, em última instância, vencedores) ou como vitoriosas (contra inimigos que

${ }^{51}$ O lado voltado para o jardim não foi preservado.

${ }^{52}$ Trata-se dos lados sul e norte. O lado voltado para o jardim não foi preservado.

${ }^{53}$ Eles aparecem, em diferentes arranjos, em 34 ábacos de capitéis.

${ }^{54}$ AYMERICUS DE PEYRACO. Chronicon. BNF Lat. 4991A fol. 160v, 10-18: "Dictusque Asquilinus, secundum intersignia operis fecit fieri portale pulcherrimum et subtillissimi operis constructum ecclesie dicti monasterii quod colligitur ex scatis ibidem sculptatis tam in claustro quam in medio pillaris magni portalis ecclesie. Nam a nomine Asquilini faciebat scatus picium in lapidibus quibusdam sculpari". "O mesmo Asquilinus [Ansquitil], segundo os símbolos que se veem na construção, fez fazer o belíssimo e sutilíssimo portal, finamente construído, da igreja abacial, e isso se pode deduzir das escamas que são esculpidas tanto no claustro quanto no meio do pilar do portal da igreja. Porque foi a partir do nome de Asquilinus que ele fez esculpir escamas de peixe em algumas pedras". Em um ponto, pelo menos, Ayeric de Peyrac está equivocado, porque o portal é posterior ao abaciado de Ansquitil, sendo provavelmente da época de seu sucessor, o abade Roger. Ver, a esse respeito, entre outros, KLEIN, Peter K. Programmes eschatologiques, fonction et réception historiques des portails du XIIe s: Moissac - Beaulieu - Saint Denis. Cahiers de Civilisation Médiévale, 33, 1990, p. 317-349, p. 320. 
simbolizam o mal) - o que indica uma visão de cristianismo e de monaquismo bastante ativo e combativo. Podemos falar que, além dos apóstolos, os "pilares" da clausura, para a comunidade de Moissac, é essa mescla de combate, sacrifício e de imitação do Cristo.

Há, entre os capitéis não-adossados, outras montagens bastante evidentes como essas, em função, sobretudo, de sua localização. Esse é o caso, por exemplo, dos santos mártires da galeria leste, e que são quase simétricos em relação ao eixo central, o abade Durand. Assim, do lado esquerdo, a partir de Durand, estão os santos de devoção regional Saturnino, Frutuoso, Eulógio e Augúrio, e, do lado direito, os santos do hagiológico principal da Igreja católica, Lourenço, Pedro e Paulo. Mais uma vez, Durand exerce um papel em uma montagem, dessa vez não só acompanhando os santos, como também os distribuindo na galeria.

A montagem simétrica é, aliás, característica de toda essa galeria, abarcando quase a totalidade de seus capitéis, tanto figurativos quanto ornamentais, tendo sempre Durand como ponto de partida para o espelhamento. ${ }^{55}$ Outra característica do modo de funcionamento dessa galeria é a ênfase nas imagens relacionadas à doação, caridade e generosidade (a adoração dos magos, a parábola de Lázaro e do rico avarento e as bodas de Canaã). Trata-se de uma nova montagem topológica, atraída pela proximidade com a sala capitular, lugar no interior do claustro onde poderiam ser assinadas cartas de doação ao mosteiro. ${ }^{56}$

Ainda nesta galeria, outro exemplo de montagem, dessa vez interna à imagem, é o capitel do ritual do lava-pés [fig. 3, pág. 245], identificado por uma inscrição

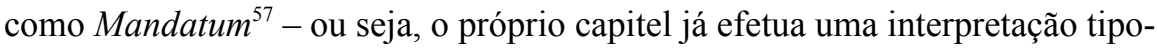
lógica dessa passagem bíblica, associando-a ao ritual que os monges deveriam realizar todo sábado ${ }^{58}$ e toda quinta-feira santa. ${ }^{59}$ Esta cerimônia poderia se realizar

$\overline{55}$ Para essa composição simétrica da galeria leste, ver: PEREIRA, Maria Cristina C. L. Le lieu et les images. Les sculptures de la galerie est du cloître de Moissac. In: HÜLSEN-ESCH, Andrea von; SCHMITT, Jean-Claude (org.). Die Methodik der Bildinterpretation. Göttingen: Wallstein, 2002, p. 415-470.

${ }^{56}$ Mesmo se o cartulário de Moissac não faz menção ao lugar onde as cartas eram assinadas, conhecemos vários casos em que a sala capitular é explicitamente citada, como nas cartas do mosteiro de Saint-Vincent du Mans. Ver: WHITE, Stephen D. Custom, kinship and gifts to saints. The Laudatio Parentum in Western France, 1050-1150. Chapel Hill/Londres: The University of North Caroline Press, 1988, p. 249, n. 100.

${ }^{57} \mathrm{O}$ termo foi retirado de uma das frases pronunciadas pelo Cristo naquela ocasião, e que serve de antífona para o ritual da quinta-feira santa: "Mandatum novum do vobis, ut diligatis invicem; sicut dilexi vos, ut et vos diligatis invicem". Jo 13, 34: "Dou-vos um novo mandamento: Amai-vos uns aos outros. Como eu vos tenho amado, assim também vós deveis amar-vos uns aos outros".

${ }_{58}^{5}$ Benedicti Regula monachorum, 35, 7; 9.

${ }^{59}$ Liber Tramitis aevi Odilonis abbatis, 1, 55. 7. DINTER (ed.). Liber Tramitis aevi Odilonis abbatis. 
na sala capitular ${ }^{60}$ e, para Pierre Sirgant, a cerimônia do Mandatum se realizaria mesmo diante deste capitel. Mas esta hipótese, de uma relação de espelho entre a imagem e o ritual, parece-nos um tanto forçada: a cena onde o Cristo está figurado está voltada para outra coluna, e não para o interior da galeria, como seria então de se esperar. Há, mais que uma relação especular, uma relação de exibição e recuo, de aproximação e afastamento. Ou seja, há um desvio causado pelo posicionamento da cena no capitel, que estabelece a distância entre o modelo crístico e a realidade dos monges. Essa montagem pelo desvio é, de certo modo, o oposto daquela que se opera em relação a Durand, de face e em face à sala capitular (e aos monges que lá entram ou que de lá saem).

A metade leste da galeria sul, a mais próxima da igreja, é a que apresenta a maior concentração de cenas da vida do Cristo - mas, novamente, intercaladas com outras passagens, sobretudo do Apocalipse. Com exceção do batismo, no capitel adossado ao pilar de ângulo, trata-se de imagens do Cristo poderoso: transfigurado no alto do monte, realizando milagres (curando o filho do centurião e a filha da cananeia) e derrotando o Diabo que o tentara no deserto. A proximidade com o altar e a igreja certamente influenciou essa polarização do Cristo, que é também reforçada pelo grupo de imagens do Apocalipse, mais concentrado na outra metade da galeria.

Nesta metade, estão as duas cidades mencionadas pelo Apocalipse, Jerusalém e Babilônia. Coerentemente, elas não estão coladas, mas são separadas por cenas do Antigo Testamento e por capitéis ornamentados. Trata-se de um outro tipo de montagem, dessa vez por contraste. ${ }^{61}$

Há outra Jerusalém representada no claustro, na galeria norte, e quase sobre o mesmo eixo que a Jerusalém da visão joanina. Mas aquela possui uma inscrição

Turnhout: Brepols, 1980 (CCM 10, p. 77-78).

${ }^{60}$ MEYVAERT, op, cit., p. 55; THOLL, Susan E. von Daum. Life according to the Rule: a monastic modification of Mandatum imagery in the Peterborough Psalter. Gesta 33/2, 1994, p. 151-158, p. 153. O Liber Tramitis não especifica o lugar onde deve se realizar o mandatum, mas insinua que se trata da sala capitular, por causa da recomendação feita aos servidores de se lavarem fora desta sala: "Primum autem cum ad mandatum conuenerint, aebdomadarii qui extituri sunt de coquina sequenti dominica pedes omnibus lauent. Postea domnus abbas, si praesens fuerit, ex una parte, prior ex altera lauent pedes, tergant et osculentur. Quod cum fuerit impletum, ueniat domnus abbas in locum suum et duo fratres lauent illi pedes, seruitores autem foras capitulum lauent". Liber Tramitis aevi Odilonis abbatis, 1, 55.7 (CCM 10, p. 77). No entanto, os Decreta Lanfranci, do século XI, que descrevem a cerimônia mais detalhadamente, precisam que ela se realiza dentro e fora da sala capitular. Decreta Lanfranci. KNOWLES, David (ed. e trad.). The monastic Constitutions of Lanfranc. Londres: Thomas Nelson, 1951, p. 35.

${ }^{61} \mathrm{Ou}$ "montagem por oposição", como Deleuze classifica o trabalho de Einsenstein, em contraste com o de Griffith. DELEUZE, Gilles, op. cit., p. 56. 
identificando-a como a Jerusalém terrestre, a que era buscada pelos cruzados, no período contemporâneo à construção do claustro. A distância e ao mesmo tempo a simetria entre as duas cidades, a celeste e a terrena, evocava o iter, o caminho que os cruzados deveriam percorrer (lembrando que esse era um dos termos mais usados na época para o que chamamos hoje de Cruzada), mas que no claustro era realizado de forma "figurativa" - em todos os sentidos da palavra.

Para concluirmos esse breve série de exemplos, uma outra montagem evidente, mas bastante menos fechada que as que expusemos anteriormente é a concentração maior de imagens veterotestamentárias na metade oeste do claustro e de imagens neotestamentárias na metade leste: assim como as igrejas, em geral orientadas em direção ao leste, o lado do sol nascente corresponde ao da maior presença crística.

Exemplos como estes poderiam se multiplicar e se complexificar, e eles fazem pensar em uma citação de João Cassiano sobre os procedimentos da exegese textual:

Quando, assim, a nossa mente pensa em uma passagem de algum salmo, deixando-o de lado, sem saber e admirando-se (disso), ela se volta a outro texto das Escrituras. Quando ela começa a revolvê-lo em si mesma, mal tendo entrado inteiramente nele, [tendo] aparecido na memória um outro testemunho, ela exclui a meditação da matéria precedente, [e] dela assim a outra, transfere-se com a introdução de outra mediação, e assim a alma sempre de um salmo revirado a [outro] salmo, passando do texto do Evangelho a [uma] leitura do Apóstolo, daí também voltando aos dizeres proféticos $(\ldots)^{62}$

O método exegético, de interpretação bíblica, segundo João Cassiano, é o que poderíamos chamar, uma vez mais nos remetendo a Deleuze, de "montagem de saltos qualitativos", ou "saltadora" (bondissante) ${ }^{63}$ Assim como nos comentários bíblicos o exegeta procedia por saltos, recuos, desvios, também no claustro há esse trabalho tão "turbilhonante" das montagens topo-lógicas, um jogo complexo de

$\overline{62}$ JOANNIS CASSIANUS. Conlationes, 10, 13. MIGNE, J. P. (ed.). PATROLOGIA LATINA. Paris: Migne, 1844-1880, 221v, v. 49, col. 840: "Cum enim capitulum cujuslibet psalmi mens nostra conceperit, insensibiliter eo substracto, ad alterius Scripturae textum nesciens stupensque devolvitur. Cumque illud in semetipsa coeperit volutare, necdum illo ad integrum ventilato, oborta alterius testimonii memoria, meditationem materiae prioris excludit, de hac quoque ad alteram, subintrante alia meditatione transfertur, et ita animus semper de psalmo rotatus ad psalmum, de Evangelii textu ad Apostoli transiliens lectionem, de hac quoque ad prophetica devolutus eloquia (...)". Trad. Eduardo Henrik Aubert.

${ }^{63}$ DELEUZE, Gilles, op. cit., p. 56. O autor novamente faz referência a um dos tipos de montagem utilizada por Einsenstein. 
associações entre as imagens e seus lugares em níveis diferentes, e não simples linearidade narrativa.

Ademais, o prestígio do claustro não condiz com uma disposição de imagens que seria aleatória. Ao contrário, havia certamente uma preocupação em criar ali, graças às imagens, um environnement à altura das atividades e expectativas, no sentido dado ao termo por Jean-Claude Bonne, onde:

Elas [certas organizações artísticas medievais] não se apresentam sob a forma de obras isoladas a considerar por elas mesmas, como em um museu ou um lugar de exposição, mas como conjuntos integrando diversos elementos e suficientemente vastos para que seja possível se deslocar dentro deles. ${ }^{64}$

Essa citação de Bonne, que parece ter sido pensada para responder a Régis de la Haye, reafirma a especificidade do claustro como um efetivo "lugar de imagens". ${ }^{65}$ Assim como diferentes ações tinham lugar no claustro, as imagens contribuíam para esses diferentes usos e esses diferentes modos de funcionamento - seja os reforçando, ecoando-os ou neles interferindo, em diferentes tipos de montagens topo-lógicas.

Recebido: 20/05/2011 - Aprovado: 01/07/2011.

${ }^{64}$ BONNE, Jean-Claude. Arte e environnement: entre arte medieval e arte contemporânea. Anais da VII Semana de Estudos Medievais, Brasília, 2009 (no prelo). "Elles [certas organizações artísiticas medievais] ne se présentent pas sous forme d'œuvres isolées à considérer pour ellesmêmes, comme dans un musée ou un lieu d'exposition, mais comme des ensembles intégrant divers éléments et assez vastes pour qu'on puisse s'y déplacer".

${ }^{65}$ A respeito dessa ideia, ver, entre outros artigos do autor, BASCHET, Jérôme. Le lieu rituel et son décor. In: Idem. L'iconographie médiévale. Paris: Gallimard, 2008, p. 67-101. 